\title{
Construct Validation of the Pictorial Implicit Association Test (PIAT): Implications for Implicit Attitudinal Research
}

\section{Authors}

\author{
Dr Susan Chequer ${ }^{1}$ \\ University of Tasmania, \\ Churchill Avenue, Sandy Bay, \\ Tasmania, Australia, 7005
}

\begin{abstract}
Dr Michael G. Quinn
Division of Psychology, School of Medicine, College of Health \& Medicine, University of Tasmania, Private Bag 30, Hobart, Tasmania, Australia, 7001
\end{abstract}

\section{Highlights}

- Novel instrument for assessing implicit attitudes without need for verbal fluency.

- The Pictorial Implicit Association Test (PIAT) was demonstrated as equivalent to the traditional verbal IAT (VIAT) and appears suitable for assessing implicit attitudes in children and the illiterate.

- Evidence of substantial error variance in IAT data that will need further investigation.

\begin{abstract}
Construct validation of the Pictorial Implicit Association Test (PIAT) was assessed using Confirmatory Factor Analytic (CFA) procedures to account for measurement error. The PIAT was compared with the traditional verbal IAT (VIAT) to examine construct validity and internal consistency. Attitudes towards Middle Eastern and European people and countries were examined using two PIATs, two VIATs and two explicit attitude questionnaires for 198 student participants. Results demonstrated convergent validity of the PIATs and VIATs, supporting the equivalency of these task formats. The PIAT appears a suitable alternative to the VIAT for use in applied behavioural research, especially with populations for whom the VIAT is inappropriate, such as young children and the illiterate. However, evidence of substantial error variance in both the PIAT and the more widely used VIAT was concerning, and suggests the need for latent modelling analytical approaches to address error variance in implicit attitudinal research.
\end{abstract}

\section{Keywords}

Implicit Attitude Test, Pictorial IAT, Child Assessment, CFA, Validity, Measurement Error

\footnotetext{
${ }^{1}$ Contact Susan on Suse.Chequer@gmail.com; Current Affiliation for Susan Chequer is: Australian Childhood Foundation, 39 Tasma Street, North Hobart, Tasmania, Australia, 7000
} 


\section{Introduction}

The Implicit Association Test (IAT; Greenwald, McGhee, \& Schwartz, 1998) has been widely used to assess implicit attitudinal bias and prejudice. IATs have been used with both clinical and community adult populations, and applied to assess many and varied attitudinal constructs (for an overview see Cooper, Blackman, \& Keller, 2015). IAT research predominantly focused on a literate adult population due to the IAT's reliance on word-based stimuli. However there has been increasing focus on expanding the participant pool by adapting the IAT to include non-verbal formats to allow for the potential of accessing implicit attitudes in very young children and the illiterate.

There have been a series of attempts to adapt the IAT for use with children, including the Pictorial IAT (PIAT; Thomas, Burton-Smith, \& Ball, 2007) for children as young as three years, the Pre-school Implicit Association Test (Cvencek, Greenwald, \& Meltzoff, 2011) for children as young as four, the Child-IAT (Rutland, Cameron, Milne, \& McGeorge, 2005) and the Children's IAT (Ch-IAT; Baron \& Banaji, 2006) both for use with children as young as six years (Cvencek et al., 2011). Specific evaluative advantages exist with the PIAT (Thomas et al., 2007), due to it being a single-modality instrument using only pictorial stimuli, and using the more intuitive approach, especially for young children, of touch-screen response. As much of attitude development occurs during the pre-school years (Gonzales, Dunlop, \& Baron, 2017; Nesdale \& Flesser, 2001), the ability for younger children to engage with the task positions the PIAT well for social psychological research investigations. While the PIAT was demonstrated to successfully be used by children as young as three years of age (Thomas et al., 2007), the need for further cross-comparison of the PIAT with the widely used Verbal IAT (VIAT; Greenwald et al., 1998) remained. The aim of the current study was to assess construct validity evidence for the PIAT with the classic and widely used VIAT as a wellresearched comparison.

\subsection{Advantages of Pictorial Stimuli Presentation in Implicit Attitude Assessment}

The PIAT offers two notable advantages over the traditional verbal IAT (VIAT) methodology. Firstly, because the PIAT avoids the need for verbal fluency, the task enables an expanded participant pool for implicit attitudinal assessment. Although developed for the 
purpose of assessing attitudes in very young children, the PIAT could be further applied to populations with lower levels of literacy or verbal fluency, such as forensic populations who are known to possess poor literacy (e.g. Greenberg, Dunleavy, \& Kutner, 2007; Schmidt, Banse, \& Imhoff, 2015) or indeed as much as $44 \%$ of the Australian population who were estimated to lack the literacy levels required for modern daily life (see PCAAC report by Australian Bureau of Statistics, 2013). The PIAT may also be used for cross-cultural research, as pictorial stimuli can transcend the requirement of specific language comprehension and issues around cross-cultural language translation (see Danziger \& Ward, 2010 for issues of language systematically influencing verbal IAT results).

The second advantage of pictorial stimuli presentation is that the task becomes more speeded. Pictorial IATs have been shown to produce significantly faster reaction times than wordbased IATs (Foroni \& Bel-Bahar, 2010; Thomas, 2008), thereby increasing the automaticity of the task (see also Baron \& Banaji, 2006; Dasgupta, McGhee, Greenwald, \& Banaji, 2000). This increased automaticity is likely due to pictorial stimuli requiring less effortful processing than word stimuli (Carr, McCauly, Sperber, \& Parmelee, 1982; Glaser \& Glaser, 1989). Higher automaticity could theoretically deliver an even more "unconscious" or unfiltered reactive impression of the participants' biases (Slabbinck, De Houwer, \& van Kenhove, 2013).

A further advantage of faster reaction times is that they allow participants to complete the same number of trials in a shorter period of time, a factor which may have numerous benefits. Firstly, it may reduce fatigue or difficulties sustaining attention for the participants, thereby potentially reducing random error variance associated with the task (Debner \& Jacoby, 1994). Secondly, faster reaction times make it more practical for researchers to run more trials than was previously practicable, which could result in increased reliability of implicit attitude measurement (see Siers \& Christiansen, 2013). Given the sometimes poor and inconsistent reliability estimates often cited for implicit attitude measures (e.g. Buhrmester, Blanton, \& Swann, 2011; Carlsson \& Agerstrom, 2016; Karpinski \& Hilton, 2001; Krause, Back, Egloff, \& Schmukle, 2010; Oswald, Mitchell, Blanton, Jaccard, \& Tetlock, 2015; Rudolph, Schröder-Abé, Schütz, Gregg, \& Sedikides, 2008), this could prove a significant advantage for the PIAT. 


\subsection{Advantages of the PIAT for assessing implicit attitudes in very young children.}

Past attempts to assess the attitudes of very young children have often been hindered by issues of limited self-reflective capacity, acquiescence and social desirability, in that children often have limited capacity to reflect on and present their own attitudes, and may attempt to adapt their views to please the researcher (Baron \& Banaji, 2006; Cvencek et al., 2011). Implicit assessment techniques appear well suited to address these concerns for child-related attitude measurement, by minimising the opportunity or requirement for self-reflection, selection or censorship (Stanley, Phelps, \& Banaji, 2008). However, standard implicit attitude measures require levels of receptive language abilities that are significantly beyond that of younger children and indeed many adults (Australian Bureau of Statistics, 2013). Given that early childhood is where attitudes are formed (Gonzales et al., 2017; Nesdale \& Flesser, 2001), it made sense to develop an implicit attitude measure that avoided the need for verbal fluency and would be intuitive and accessible for very young participants.

There have been two approaches to adapting the standard verbal format of the IAT (Greenwald et al., 1998) for use with children. One approach was to use a mix of pictures and words, with a recorded adult voice simultaneous presenting the word stimuli for the young participants (e.g. the Ch-IAT, Baron \& Banaji, 2006; and PSIAT, Cvencek et al., 2011). This novel approach requires the children to respond to both visual and auditory stimuli at the same time. Dual stimuli require simultaneous processing in different brain structures (i.e. the primary visual cortex on the occipital lobe and the primary auditory cortex on the temporal lobe, Grivas, Down, \& Carter, 2000), and it is largely unknown what impact, if any, such dual processing would have on the IAT effect, let alone the cognitive load effects for children of simultaneous processing. It is further noted that pictures and words are processed differentially, with pictures engaging visual and perceptual systems most and words engaging semantic and long-term memory systems most (Carnevale, Fujita, Han, \& Amit, 2015; Foroni $\&$ Bel-Bahar, 2010). It is thus sensible to reduce potential confounds by employing a single modality (i.e. pictures) for use in the assessment of implicit attitudes (as per the Child-IAT, Rutland et al., 2005; and the PIAT, Thomas et al., 2007). Given the PIAT has demonstrated a wider potential participant cohort, it is the primary focus of this validation paper. 


\subsection{Psychometric Validation of the Pictorial Implicit Association Test}

Past psychometric validations of implicit attitude measures have often demonstrated low or variable reliability and validity estimates (e.g. Bar-Anan \& Nosek, 2014; Carlsson \& Agerstrom, 2016; Cunningham, Preacher, \& Banaji, 2001; Gawronski, Morrison, Phills, \& Galdi, 2017; Karpinski \& Hilton, 2001; Krause et al., 2010; Rae \& Olson, 2018). For instance, a recent meta-analysis of child-related IATs demonstrated considerable variability across measures, with test-retest reliability ranging from $r=.17$ to $r=+.62$, and predictive validity between IAT and behaviour ranging from no relationship $r=.02$ to strong positive relationships $r=.52$ (Rae \& Olson, 2018). Such variability is problematic for the consistent use of IAT measures and raises concerns for the effectiveness of these tools. Contemporary research suggests measurement error may be significantly impacting on reliability and validity estimates for implicit attitude measures (Cunningham et al., 2001). Previous efforts to estimate reliability and validity for the PIAT revealed only moderate convergence between equivalent VIAT and PIAT measures (Thomas, 2008). However, this and other attempts to assess the reliability or validity of child-related IATs (e.g. Rae \& Olson, 2018; Slabbinck et al., 2013; Williams \& Steele, 2016) have relied upon traditional analytical approaches, such as the general linear model, that assume random distribution of error variance (Tabachnick \& Fidell, 2013).

The assumption of random error variance distribution is likely flawed for the IAT as it requires error variance to influence the congruent and incongruent trials equally in order to have little overall impact on the IAT scores (for an overview of the IAT procedure see Greenwald et al., 1998). This is very unlikely given the IAT's incongruent trials are demonstrably more cognitively taxing than congruent trials (Williams \& Themanson, 2011). Greater task difficulty usually results in greater random error variance (Brown \& Heathcote, 2008), as well as increased influence from systematic sources of error such as task-switching ability and processing speed (Blanton, Jaccard, Gonzales, \& Christie, 2006; Fiedler, Messner, \& Bluemke, 2006; Stülpnagel \& Steffens, 2010). This implies that validity estimates for implicit attitude measures need to take into consideration non-random error distribution. Analytical techniques such as Confirmatory Factor Analysis (CFA; Jöreskog, 1969), are well suited for this, as CFA provides a means to estimate and control for error variance. However, as yet, such techniques have not been widely used in implicit attitudinal research. 


\subsection{The Present Study}

The aim of the current study was to assess the reliability and construct validity of Thomas et al.'s (2007) PIAT, by examining convergent validity with the classic Verbal IAT (VIAT) using Confirmatory Factor Analytic (CFA) procedures. Two versions of the PIAT and VIAT were developed; one that examined implicit racial biases between Middle Eastern and European people, referred to as the Racial PIAT/VIAT; the other, examined implicit "country" bias between Middle Eastern and European countries, referred to as the Country PIAT/VIAT. Racial biases towards Arabs and the Middle East were selected as trait constructs due to strong evidence of antipathy towards persons from the Middle East documented in Australia (Dunn, Forrest, Burnley, \& McDonald, 2004; Dunn et al., 2008; Islam \& Jahjah, 2001), the current testing context. Two explicit attitude tasks measuring equivalent constructs were also employed to examine discriminant validity. Due to the limitations of applying the VIAT for use with children, as outlined previously, the current study required an adult population to facilitate appropriate comparison of the VIAT and PIAT methodologies.

\section{Materials and Methods}

This research and its methodology were approved by the Tasmanian Social Sciences Human Research Ethics Committee (HREC Reg No. H0010891). All measures, manipulations, and exclusions in this study are disclosed within this methods section. In accordance with ethical guidelines data cannot be made publicly available.

\subsection{Participants}

One hundred and ninety-eight students (144 [72\%] female) from the University of Tasmania, Australia, with a mean age of 26.03 years ( $S D=11.10$ years) participated in the study. The majority of participants identified their ethnicity as "Australian" ( $n=174$ [88\% of the sample]). Students received course credit for participation.

\subsection{Apparatus}

The VIATs and PIATs were presented individually on a laptop PC running Windows, and using the Inquisit software package (Millisecond Software, 1996). Explicit attitude questionnaires were provided in paper form. 


\subsubsection{Verbal Implicit Association Tests (VIATs).}

Two traditional IAT measures depicting verbal word stimuli (VIATs) were developed in accordance with Greenwald, et al. (1998). The VIATs used standard Pleasant and Unpleasant word stimuli, such as "love" and "hatred". The Racial VIAT employed typically Middle Eastern and European first names, for instance "Habib" and "Harry". The Country VIAT used Middle Eastern and European country names, such as "Iraq" and "Italy".

\subsubsection{Pictorial Implicit Association Tests (PIATs).}

Two PIAT measures depicting only pictorial stimuli were developed in accordance with Thomas, et al. (2007). These tasks presented graphical stimuli instead of the usual word stimuli. The PIATs in this study utilised Positive and Negative facial icons or 'emoticons' as well as faces of Middle Eastern and European people for the Racial PIAT, and easily recognisable buildings from Middle Eastern and European countries (e.g. mosques and churches, and other distinctive landmarks) for the Country PIAT (stimuli available on request from author). All stimuli were piloted to ensure equal valence.

\subsubsection{Explicit attitude questionnaires.}

The Modern Racism Scale (MRS; McConahay, Hardee, \& Batts, 1981) consists of six statements regarding 'Black' people in the USA. Participants rate their level of agreement on a five-point Likert scale. In the present study, the MRS statements were adjusted to assess Anti-Arab prejudice rather than Anti-Black sentiment, i.e. "Many Arabs living in Australia miss out on jobs or promotions because of racial discrimination". Such alteration of the MRS is standard place (e.g. Barlow, Louis, \& Terry, 2010 who adapted MRS to assess attitudes towards Aboriginal Australians; Echebarria-Echabe \& Guede, 2007 who adapted the MRS to assess attitudes towards Arabs). The six racially relevant items were located within a list of 20 statements requiring the participants' opinion on a variety of other socially-sensitive issues: including cannabis use, suicide, homosexuality and global climate change. This aimed to minimise the focus on race for the participants. The questionnaire provided to participants was titled 'Student Opinions'. The additional components were not used within the analysis.

The Travel Destination Questionnaire, devised for the current research, comprised a list of 18 countries (six from Europe, six from the Middle East and six from Asia). Participants rated on a five-point Likert scale how much they would like to visit each of the destinations. The 
countries were selected from a list of tourism statistics by country with the top six most visited destinations for each area chosen (United Nations, 2009). Information regarding visiting destinations within Asia were used as 'filler' items, and not used within the analysis

\subsection{Procedure}

Following consent procedures, each participant completed six empirical implicit attitude measures and two explicit attitude measures individually. All participants completed two practice IATs of a non-related attitudinal construct (i.e. Flower-Insect, as per Greenwald et al., 1998) prior to attempting the empirical attitude measures. This aimed to minimise the confounding influence of task familiarity (see Greenwald, Nosek, \& Banaji, 2003). Task completion was fully randomised and counterbalanced to reduce the likelihood of order effects. For the IATs, all of the practice blocks were composed of 40 trials, with the four empirical blocks consisting of 102 trials each.

\subsection{Scoring and Data Analysis}

2.4.1. Scoring and Data Analysis of the Implicit Association Tests (PIAT \& VIAT).

Participants with any data missing or latencies less than $300 \mathrm{~ms}$ for more than $10 \%$ of an IAT's trials were excluded (Greenwald et al., 2003). All practice trials were then removed (as per Nosek, Greenwald, \& Banaji, 2006) along with any individual response latencies greater than 10,000ms (Greenwald et al., 2003). The first two trials of each empirical block were also deleted in accordance with Greenwald et al. (1998). Any deleted trials (i.e. those with response latencies above $10,000 \mathrm{~ms}$ ) were replaced with the response time of the second trial to avoid missing data.

For each participant, the IAT scores were divided into four equivalent data parcels consisting of 25 response latencies from each of the first congruent, second congruent, first incongruent and second incongruent blocks of data. This enabled four roughly equivalent IAT scores to be produced for each participant, as per the scoring recommendations of Greenwald et al. (2003). The four sets of IAT scores for the combined participant pool provided the CFA input data. 


\subsubsection{Scoring and Data Analysis of the Explicit Attitude Questionnaires.}

The relevant MRS items were scored as per standard methods, such that larger scores were indicative of stronger expressed anti-Arab sentiment. TDQ scoring required the raw responses for the European, and Middle Eastern countries to be tallied separately. This resulted in two scores out of 30 for each participant, with higher scores indicating a higher stated desire for visiting that location.

\subsection{Statistical Analyses}

CFA analyses were performed using the robust Maximum Likelihood estimation (MLM) in Mplus 6.1 (Muthén \& Muthén, 2010). Internal construct validity was assessed for each version of the PIAT/VIAT separately using single-factor CFA, where each of the four parcels for each implicit attitude task was specified as an indicator for the implicit attitude factor. Minimum factor loadings of .32 were indicative of meaningful relationships within the CFA models, in accordance with Gorsuch (1983). Evaluation of model fit was determined by the goodness-of-fit indices. As the chi-square likelihood ratio test statistic $\left(\chi^{2}\right)$ is affected by sample size (Brown, 2015), evaluation of model fit was determined by the approximate fit indices: root-mean-square error of approximation (RMSEA), the standardised root mean square residual (SRMS), and the comparative fit index (CFI). Hu and Bentler (1999) suggest good fit is demonstrated by RMSEA values close to or below .06, and SRMR values close to or below .08. CFI values close to or above .95 are indicative of good model-data fit, with acceptable fit determined with values above .90 (Brown, 2006).

Factor loadings from the CFAs were used to calculate Composite Reliability (CR) and Average Variance Extracted (AVE) for each of the IATs (see Fornell \& Larcker, 1981; Raykov, 1997). CR provides an assessment of internal consistency similar to a summated scale, by assessing the reliability of the latent construct rather than the individual test items. Unless items are tau-equivalent, $\mathrm{CR}$ is viewed as a more dependable estimator of internal consistency than Cronbach's alpha (Raykov, 1997). AVE provides an assessment of how much latent trait construct is accounted for by the IAT scores, delivering what is essentially a test of internal convergent validity. AVE values greater than .50 are considered satisfactory because they indicate that at least $50 \%$ of the variance in a measure is due to the hypothesised underlying trait, with the remaining proportion an indication of measurement error (Fornell \& 
Larcker, 1981). A result of greater than .50 implies good validity for both the construct and the individual variables, revealing acceptable internal convergent validity for the measure.

Convergent and discriminant validity evidence for the PIAT were assessed using a threefactor CFA model; for each of the two attitude constructs, covariances were specified between the PIAT, VIAT and relevant explicit attitude questionnaire. Convergent validity would be indicated by moderate to strong covariances between the VIAT \& PIAT. Discriminant validity would be demonstrated if these inter-implicit covariances were significantly higher than the correlations between the PIAT/VIAT and the relevant explicit attitude measures. Measures of model fit were evaluated as per the above criteria.

\section{Theory}

The Pictorial IAT (PIAT; Thomas et al., 2007) was adapted from the classic verbal IAT (Greenwald, et al., 1998) to address limitations of a strictly word-based measure for implicit attitudes. Prior to applied use of this measure, the PIAT requires validation with an appropriate comparison, in this case the verbal IAT (VIAT), a comparison that requires a literate adult population. Due to concerns of excessive measurement error associated with implicit measurement techniques, structural equation modelling (SEM) analytical approaches were applied to assess the construct validity of the PIAT. This provided a novel approach for SEM and delivered greater insight into the trait and error composition of IAT scores.

\section{Results}

\subsection{Internal Construct Validity Analysis of PIATs \& VIATS}

The results of the single-group CFA for the Racial PIAT are depicted in Figure 1. The results showed acceptable goodness-of-fit indices for this model: $\chi^{2}(2, N=198)=5.88, p=.05$; $\mathrm{CFI}=.980 ; \mathrm{RMSEA}=.099 ; \mathrm{SRMR}=.027$. The results of the single-group CFA for the Country PIAT are depicted in Figure 2. The goodness-of-fit indices for this model were good: $\chi^{2}(2$, $N=198)=.13, p=.94 ; \mathrm{CFI}=1.000 ; \mathrm{RMSEA}<.001 ; \mathrm{SRMR}=.004$. All indicator parcels loaded significantly and substantively onto the latent factor for each model, with all loading above .58 (well above the .32 cut-off as per Gorsuch, 1983). This demonstrates that the parcels provided a solid measure of the trait construct. High and significant error variances were 
noted however, indicating significant levels of random error variance exist in PIAT effect scores.

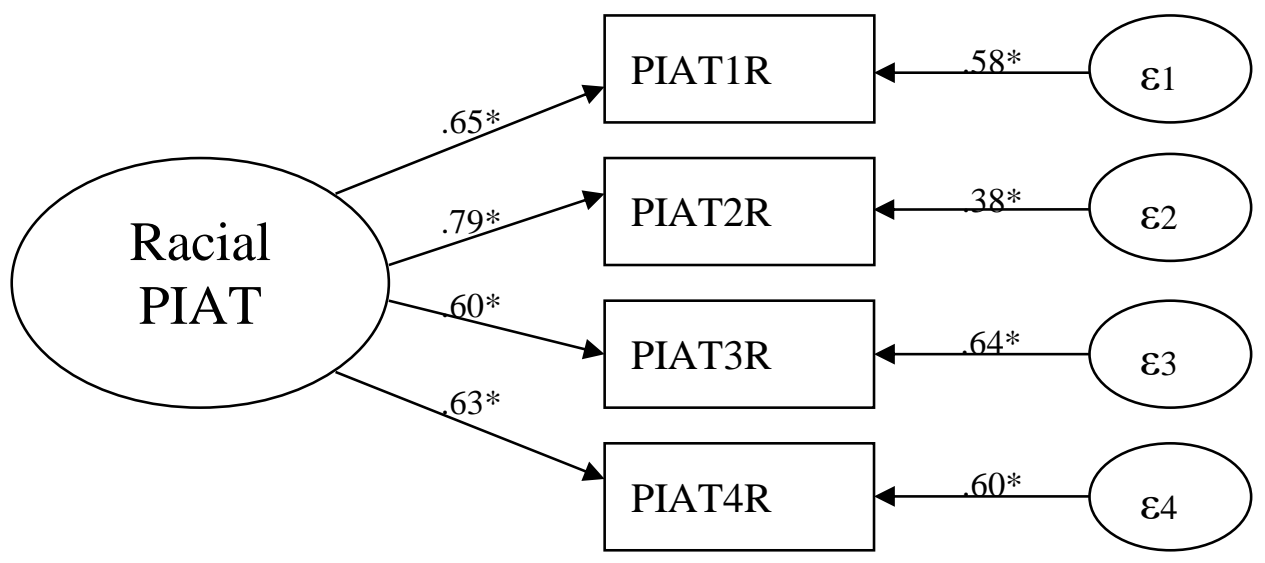

Figure 1. CFA model of the Racial PIAT depicting standardised factor loadings (STDYX) for each of the variables and residuals. $* p<.001$.

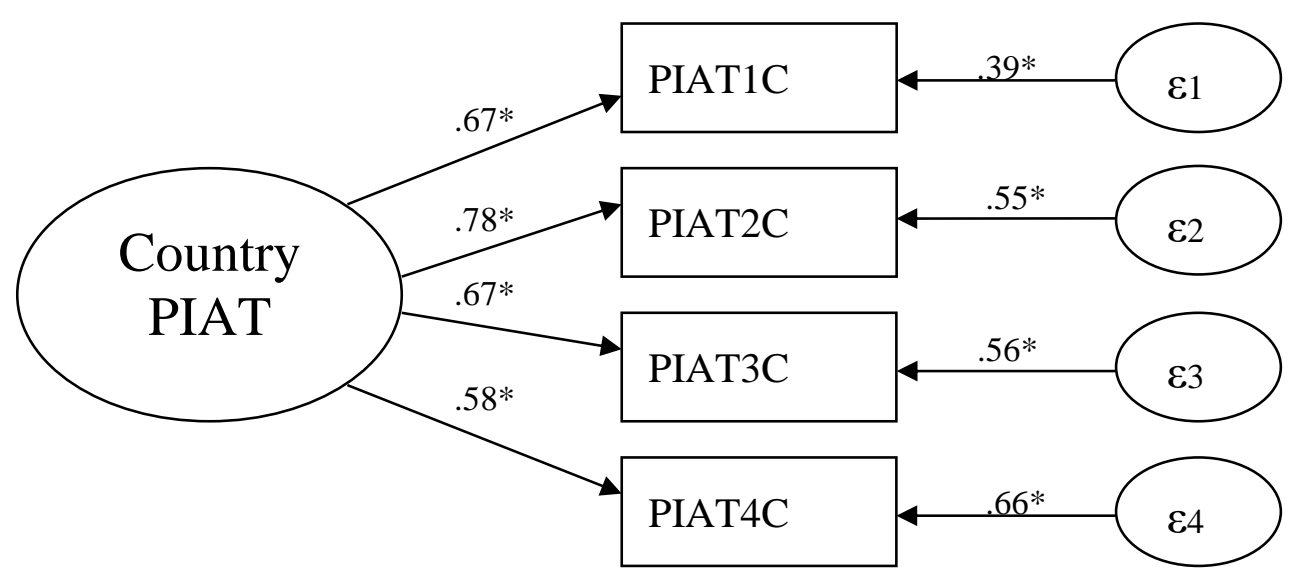

Figure 2. CFA model of the Country PIAT depicting standardised factor loadings (STDYX) for each of the variables and residuals. ${ }^{*} \mathrm{p}<.001$.

The results of the single-group CFA for the Racial VIAT are depicted in Figure 3, and for the Country VIAT, in Figure 4. The goodness-of-fit indices for both models were within acceptable limits: Racial VIAT, $\chi^{2}(2, N=198)=5.88, p=.05 ;$ CFI=.980; RMSEA=.099; $\mathrm{SRMR}=.027$; Country VIAT, $\chi^{2}(2, N=198)=3.73, p=.16$; CFI=.989; RMSEA=.066; $\mathrm{SRMR}=.022$. All indicator parcels loaded significantly onto the latent factor for each model $(\geq 0.58)$, but again high and significant error variances were also evident. 


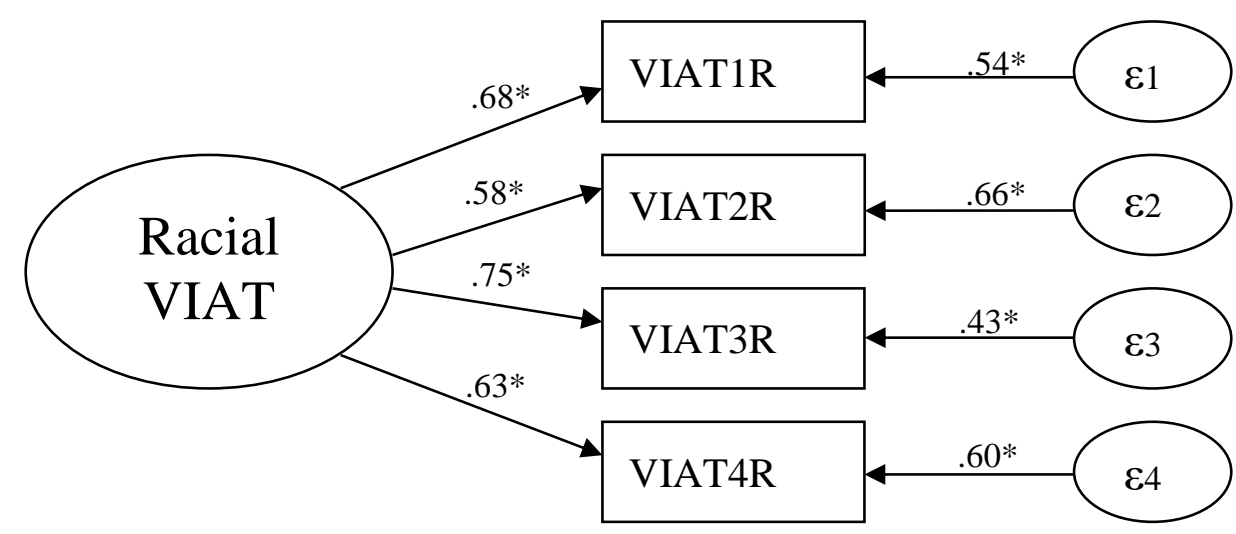

Figure 3. CFA model of the Racial VIAT depicting standardised factor loadings (STDYX) for each of the variables and residuals. ${ }^{*} p<.001$.

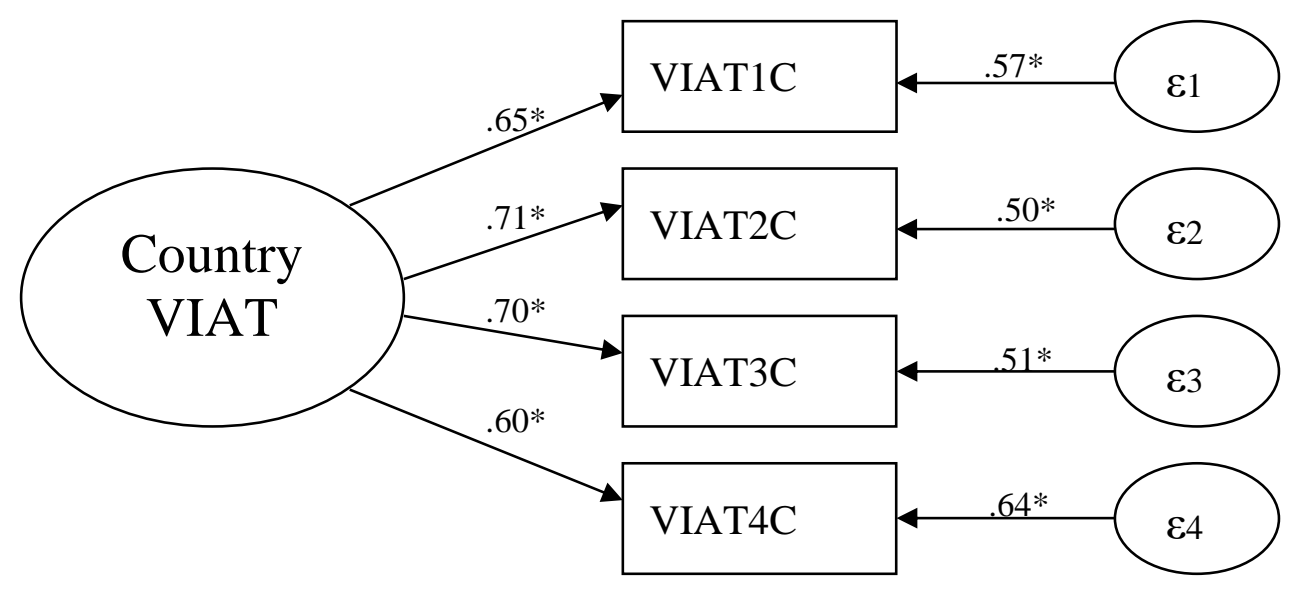

Figure 4. CFA model of the Country VIAT depicting standardised factor loadings (STDYX) for each of the variables and residuals. ${ }^{*} \mathrm{p}<.001$.

\subsection{Internal Consistency Results for the Implicit Attitude Measures}

Composite Reliability (CR) and Average Variance Extracted (AVE) statistics for all measures are shown in Table 1. All verbal and pictorial IATs were shown to possess good internal consistency, with CR estimates well above .70 (see Raykov, 1997). However, AVE estimates were low, failing to meet the required benchmark of .50 (Fornell \& Larcker, 1981), thus demonstrating unacceptable internal convergent validity as trait variance was not the biggest contributor to the IAT scores. Rather, the IAT effect scores appear to be composed of 
more error than trait variance, with random error variance accounting for just over $50 \%$ of the IAT scores.

Table 1.

Composite Reliability and Average Variance Extracted Statistics for the IATs and APTs

\begin{tabular}{lcc}
\hline & $\begin{array}{c}\text { Composite } \\
\text { Reliability }\end{array}$ & $\begin{array}{c}\text { Average Variance } \\
\text { Extracted }\end{array}$ \\
\hline Racial VIAT & .76 & .44 \\
Country VIAT & .76 & .44 \\
Racial PIAT & .76 & .45 \\
Country PIAT & .77 & .46 \\
\hline
\end{tabular}

\subsection{Convergent and Discriminant Validity Results for the Pictorial IAT using Confirmatory}

Factor Analysis

CFAs were applied to examine convergent and discriminant validity for the PIAT, VIAT and explicit questionnaire for each of two attitude constructs. The results of the three-factor CFA model for the Racial attitude construct are depicted in Figure 5. The goodness-of-fit indices for this model were: $\chi^{2}(41, \mathrm{~N}=198)=42.77, p=.40 ; \mathrm{CFI}=.997$; RMSEA=.015; SRMR=.041. All four of the fit indices found this was of good fit, supporting the convergent validity of the PIAT with the VIAT, with a strong positive covariance. The inter-implicit covariance $(\rho=.57)$ was significantly larger than the implicit-explicit covariance between the PIAT and the Modern Racism Scale $(\rho=.25, z=3.87, p<.001)$. These results support the discriminant validity of the PIAT and questionnaire measure for the racial bias construct. 


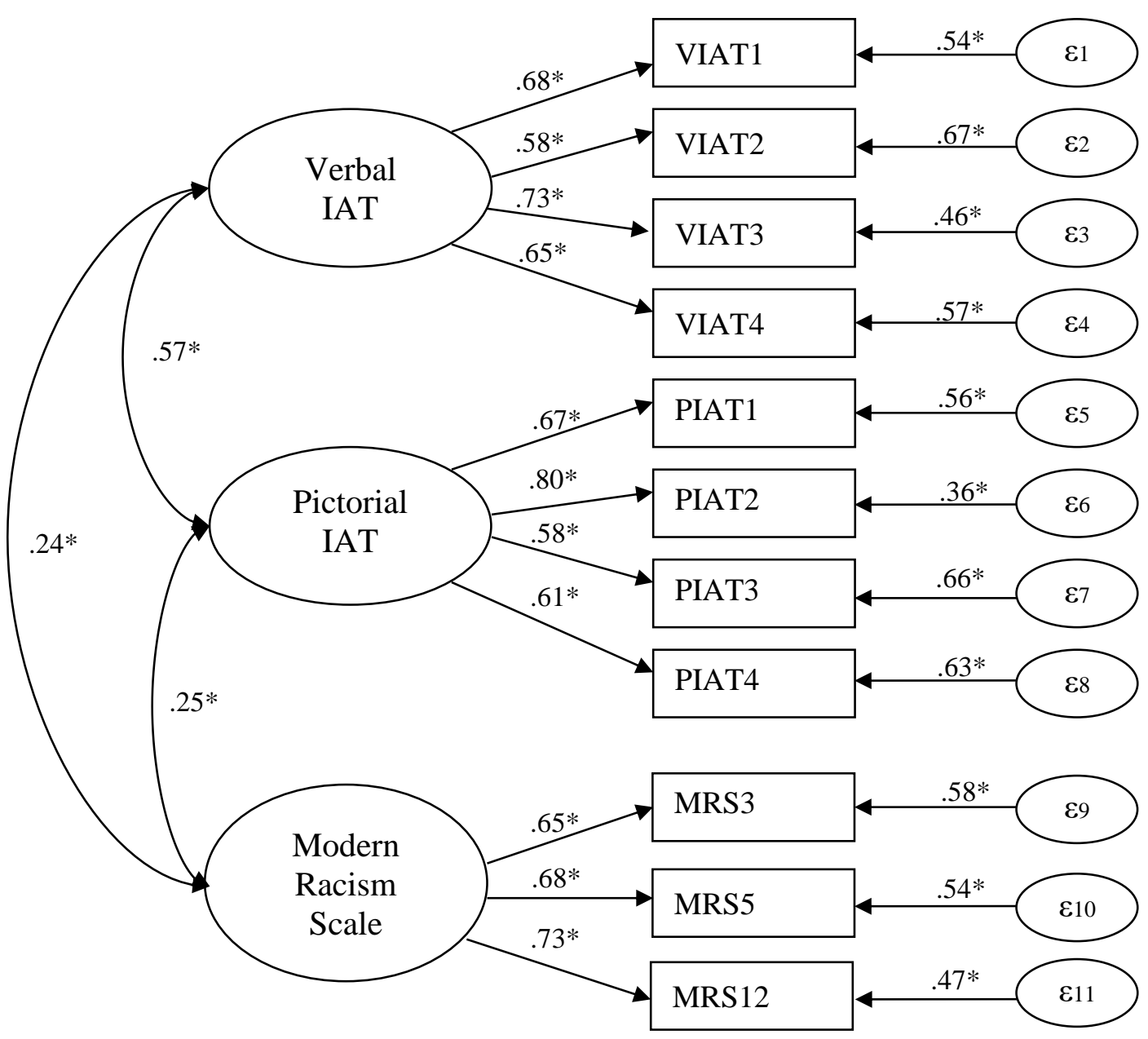

Figure 5. CFA model of the Racial attitude construct assessed by implicit and explicit attitude tasks. The standardised factor loadings (STDYX) for each of the variables and residuals are

The results of the three-factor CFA model for the Country attitude construct are depicted in Figure 6. The goodness-of-fit indices for this model were: $\chi^{2}(60, \mathrm{~N}=198)=56.92, p=.59$; $\mathrm{CFI}=1.000 ; \mathrm{RMSEA}>.001 ; \mathrm{SRMR}=.033$. All four of the fit indices indicate the data fit this model well. The strong positive covariance between the latent IAT measures provide support for the convergent validity of the PIAT with the VIAT within the country attitude construct. The covariance between the VIAT and the PIAT was again larger $(\rho=.53)$ than between the PIAT and the explicit attitudinal measure (PIAT TDQ; $\rho=.38$ ), though the difference was only at trend levels of statistical significance $(z=1.88, p=.06)$. 


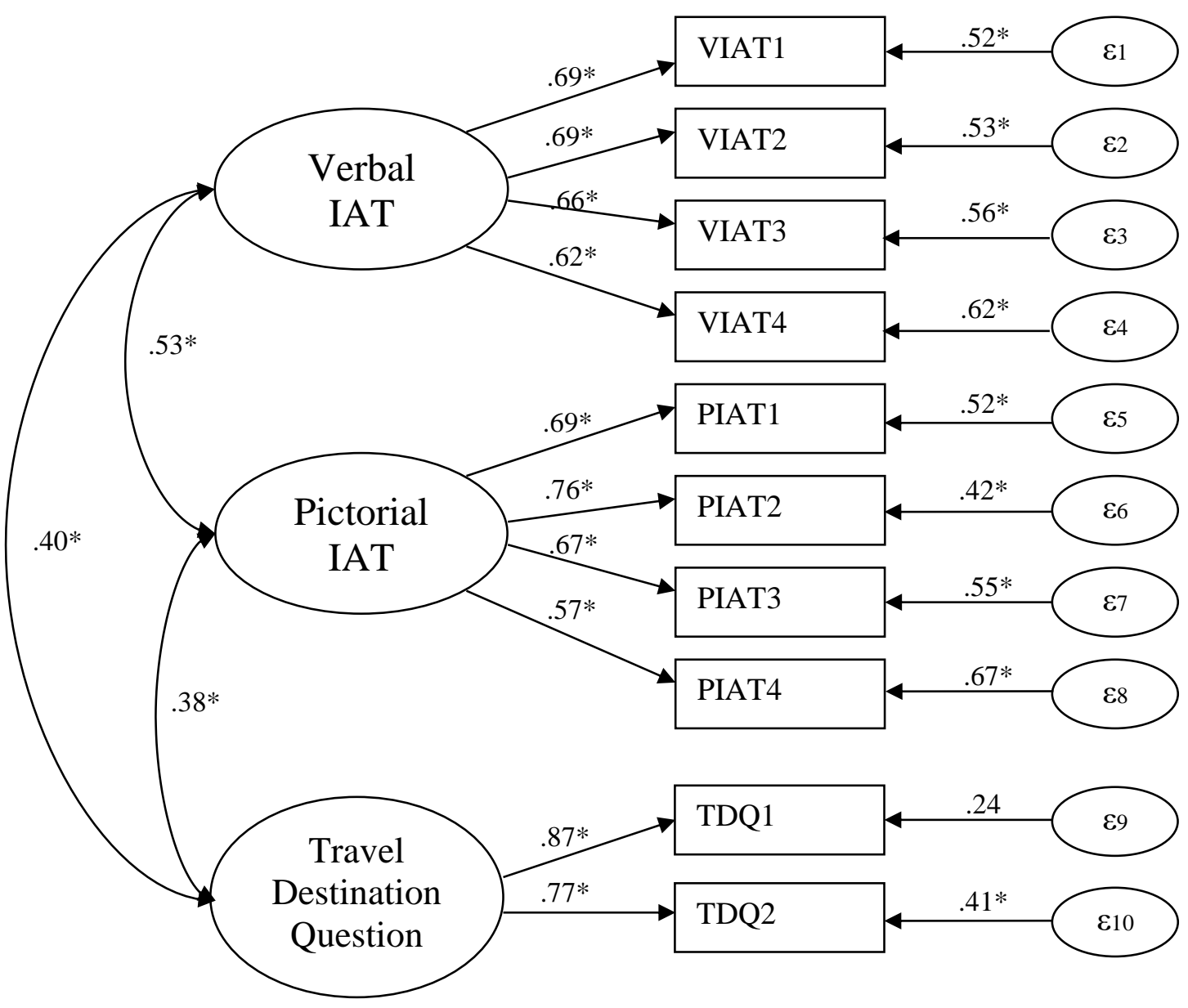

Figure 6. CFA model of the Country attitude construct assessed by implicit and explicit attitude tasks. The standardised factor loadings (STDYX) for each of the variables and residuals are depicted. ${ }^{*} \mathrm{p}<.001$.

\section{Discussion}

The aim of this study was to assess the construct validity of the PIAT in comparison with the VIAT, and doing so using CFA to account for error variance that may differentially affect IAT trial types. The psychometric properties of the PIAT were demonstrated to be highly comparable to the traditional VIAT. The PIAT itself showed reasonable internal consistency as measured by CR. As expected the inter-implicit correlation between the PIAT and VIAT were stronger than the implicit-explicit relationship for both attitude constructs, showing strong convergent validity for the PIAT with the VIAT, and evidence of discriminant validity 
with explicit attitude measures. This supports previous research demonstrating implicit and explicit traits as related but distinct concepts (Nosek \& Smyth, 2007). Overall, there appeared to be reasonable psychometric support for the construct validity of the PIAT, especially with regards to the comparability of the PIAT to the VIAT. However, it was notable that AVE calculations revealed more error that trait variance being present in all IAT scores, irrespective of the IAT type.

\subsection{Psychometric Support for the PIAT}

The PIATs were shown to be comparable to the VIATs as the respective latent attitude constructs were strongly correlated in the three-factor CFA model. A strong inter-implicit correlation between the PIATs and VIATs is an important finding given previous research that reported only small to medium-sized correlations between verbal and pictorial IAT formats using traditional correlational analyses (Carnevale et al., 2015; Foroni \& Bel-Bahar, 2010; Thomas, 2008). The finding of improved inter-implicit correlations following the partialling of error variance supports the notion that random error variance may be creating an upper limit for reliability and validity estimates in implicit attitudinal research (Cole \& Maxwell, 2003; Cunningham et al., 2001). In effect, error variance may have been attenuating the observed relationships between constructs, or, as in this case, measurement techniques assessing the same construct, thereby hindering convergent validity estimates (see Carlsson \& Agerstrom, 2016; Coenders \& Saris, 2000; Cunningham et al., 2001).

The use of latent modelling techniques in this paper, which account for error variance by assessing latent rather than observed scores, has increased the accuracy of this psychometric evaluation. The conceptual explanation of error variance attenuating observed relationships is supported by the consistent psychometric findings across the four empirical IATs used in the current study. This consistency is in contrast to the typically variable psychometric estimates reported for IATs in the past (see Foroni \& Bel-Bahar, 2010 for discussion; Hofmann \& Schmitt, 2008; Rudolph et al., 2008). In summary, it is likely that the failure to consider error variance has contributed to the inconsistencies and poor psychometric estimates in past IAT research. 


\subsection{Implications for the use of the PIAT}

The above findings provide some support for the construct validity of the PIAT, with the task performing very comparably to the traditional VIAT in all analyses. This is the first psychometric support for the construct validity of a fully pictorial IAT and indicates the PIAT may be a viable alternative to the VIAT for applied research. With the advantages of no requirement for verbal comprehension and fluency, the PIAT may allow for expanded application of implicit attitudinal research, to include young children, the illiterate, or populations non-fluent in English. This may allow for diverse research enquiries that have previously been problematic to examine, such as: implicit attitude development and the formation of implicit stereotypes in children (e.g. Cvencek et al., 2011; Dohnt \& Tiggemann, 2005; Gonzales et al., 2017; Rutland et al., 2005; Thomas et al., 2007); research regarding prison populations (known to possess poor average literacy levels, Greenberg et al., 2007), such as examining socially unacceptable attitudes regarding sexual offending or victim selection that might aid in understanding recidivism risks (e.g. Babchishin, Nunes, \& Hermann, 2013; Schmidt et al., 2015); and for cross-cultural and cross-language research, transcending the need for specific language comprehension and language translation (e.g. Danziger \& Ward, 2010). The PIAT thus offers the advantages of simpler task requirements, no need for verbal fluency, and faster trial times, and should be seen as a feasible alternative to the VIAT for applied behavioural research.

\subsection{High Measurement Error in Implicit Attitudinal Measurement: Implications and future directions for implicit attitudinal research}

However, there is a significant caveat to the above comments. A notable and somewhat concerning finding across all the IATs, both the classic VIATs and the PIATs, was the presence of considerable random error variance. Results estimated that less than $50 \%$ of the IAT effect score is comprised of trait variance; this suggests that more than half the variance of an IAT score is error variance. Whilst the magnitude of this error component may be surprising, the presence of significant error in IAT data should certainly be expected for two key reasons. Firstly, both forms of the IAT rely on speeded responding, a format known to result in greater non-trait variance than non-timed assessment (Poitou \& Pouget, 2012). Secondly, attitudinal constructs are known to be less reliably examinable than more overt constructs such as cognitive functioning (Spector, 2006). Thus, a sizeable error component is understandable, but this study uncovered that the level of error in IAT data provides a 
potential threat to the task's validity. This echoes concerns for the validity of implicit attitude measures more broadly (see Blanton et al., 2009; Carlsson \& Agerstrom, 2016; Oswald, Mitchell, Blanton, Jaccard, \& Tetlock, 2013; Oswald et al., 2015; Rae \& Olson, 2018). Clearly the confounding effects of error variance on IAT data require further investigation and necessitate the use of analytical strategies to address the error component (see also Cunningham et al., 2001; Siers \& Christiansen, 2013), rather than the more traditional approaches based on the general linear model. CFA was demonstrably effective at addressing error variance in the present study and appears well suited to addressing this concern in future IAT research.

\subsection{Conclusions}

The present study has provided psychometric evidence of construct validity for the PIAT. The PIAT was shown to be comparable to the traditional verbal IAT and shows discriminant validity with explicit attitudinal measures. The current study also revealed that error variance is a significant contributor to implicit attitudinal scores, and must be accounted for in order to reliably assess implicit attitudinal constructs. The PIAT thus appears a suitable alternative to the VIAT for applied behavioural research, but the use of latent modelling is strongly encouraged to address error variance in the data and allow for greater confidence in IAT findings. 


\section{References}

Australian Bureau of Statistics. (2013). Programme for the International Assessment of Adult Competencies (PIAAC). (4228.0). Canberra: Australian Government Retrieved from http://www.abs.gov.au/ausstats/abs@.nsf/Lookup/by\%20Subject/4228.0 20112012 Main\%20Features Preliminary\%20findings 99.

Babchishin, K. M., Nunes, K. L., \& Hermann, C. A. (2013). The validity of Implicit Association Test (IAT) measures of sexual attraction to children: A meta-analysis. Archives of Sexual Behavior, 42, 487-499. doi:10.1007/s10508-012-0022-8

Bar-Anan, Y., \& Nosek, B. A. (2014). A compartive investigation of seven indirect attitude measures. Behavioral Research Methods, 46, 668-688. doi:10.3758/s13428-013$0410-6$

Barlow, F. K., Louis, W. R., \& Terry, D. J. (2010). Minority report: Social identity, cognitions of rejection and intergroup anxiety predicting prejudice from one racially margnialized group towards another. European Journal of Social Psychology, 40, 805-818. doi:10.1002/ejsp.651

Baron, A. S., \& Banaji, M. R. (2006). The development of implicit attitudes: Evidence of race evaluations from ages 6 and 10 and adulthood. Psychological Science, 17, 53-58. doi:10.1111/j.1467-9280.2005.01664.x

Blanton, H., Jaccard, J., Gonzales, P. M., \& Christie, C. (2006). Decoding the implicit association test: Implications for criterion prediction. Journal of Experimental Social Psychology, 42, 192-212. doi:10.1016/j-jesp.2005.07.003

Blanton, H., Jaccard, J., Klick, J., Mellers, B., Mitchell, G., \& Tetlock, P. E. (2009). Strong claims and weak evidence: Reassessing the predictive validity of the IAT. Faculty Scholarship. University of Pennsylvania Law School. Pennsylvania. Retrieved from http://scholarship.law.upenn.edu/faculty_scholarship/1532

Brown, S. D., \& Heathcote, A. (2008). The simplest complete model of choice response time: Linear ballistic accumulation. Cognitive Psychology, 57, 153-178. doi:10.1016/j.cogpsych.2007.12.002

Brown, T. A. (2015). Confirmatory Factor Analysis for applied research (2nd ed.). New York: Guilford Press. 
Buhrmester, M. D., Blanton, H., \& Swann, W. B. (2011). Implicit self-esteem: Nature, measurement, and a new way forward. Journal of Personality and Social Psychology, 100, 365-385. doi:10.1037/a0021341

Carlsson, R., \& Agerstrom, J. (2016). A closer look at the discrimination outcomes in the IAT literature. Scandinavian Journal of Psychology, 57, 278-287. doi:10.1111/sjop.12288

Carnevale, J. J., Fujita, K., Han, H. A., \& Amit, E. (2015). Immersion versus transcendence: How pictures and words impact evaluative associations assessed by the Implicit Association Test. Social Psychological and Personality Science, 6, 92-100. doi:10.1177/1948550614546050

Carr, T. H., McCauly, C., Sperber, R. D., \& Parmelee, C. M. (1982). Words, pictures, and priming: On semantic activation, conscious identification, and the automaticity of information processing. Journal of Experimental Psychology, Human Perception and Performance, 8, 757-777. doi:10.1037/0096-1523.8.6.757

Coenders, G., \& Saris, W. E. (2000). Systematic and random method effects. Estimating method bias and method variance. Metodoloski Zvezki, 15, 55-74.

Cole, D. A., \& Maxwell, S. E. (2003). Testing mediational models with longitudinal data: Questions and tips in the use of Structural Equation Modelling. Journal of Abnormal Psychology, 112, 558-577. doi:10.1037/0021-843X.112.4.558

Cooper, J., Blackman, S., \& Keller, K. (2015). The Science of Attitudes. New York: Routledge.

Cunningham, W. A., Preacher, K. J., \& Banaji, M. R. (2001). Implicit attitude measures: Consistency, stability, and convergent validity. Psychological Science, 12, 163-170. doi:10.1111/1467-9280.00328

Cvencek, D., Greenwald, A. G., \& Meltzoff, A. N. (2011). Measuring implicit attitudes of 4year-olds: The Preschool Implicit Association Test. Journal of Experimental Child Psychology, 109, 187-200. doi:10.1016/j.jecp.2010.11.002

Danziger, S., \& Ward, R. (2010). Language changes implicit associations between ethnic groups and evaluation in bilinguals. Psychological Science, 21, 799-800. doi:10.1177/0956797610371344

Dasgupta, N., McGhee, D. E., Greenwald, A. G., \& Banaji, M. R. (2000). Automatic preference for white Americans: Eliminating the familiarity explanation. Journal of Experimental Social Psychology, 36, 316-328. doi:10.1006/jesp.1999.1418 
Debner, J. A., \& Jacoby, L. L. (1994). Unconscious perception: Attention, awareness and control. Journal of Experimental Psychology, 20, 304-317. doi:10.1037/h0043350

Dohnt, H. K., \& Tiggemann, M. (2005). Peer influences on body dissatisfaction and dieting awareness in young girls. British Journal of Developmental Psychology, 23, 103-116. doi:10.1348/026151004X20658

Dunn, K. M., Forrest, J., Burnley, I., \& McDonald, A. (2004). Constructing racism in Australia. Australian Journal of Social Issues, 39, 409-430.

Dunn, K. M., Forrest, J., Ip, D., Babacan, H., Paradies, Y., \& Pedersen, A. (2008). Challenging Racism: The anti-racism research project. Paper presented at the 4Rs Conference: Rights, reconciliation, respect, responsibility, Sydney, Australia.

Echebarria-Echabe, A., \& Guede, E. F. (2007). A New Measure of Anti-Arab Prejudice: Reliability and Validity Evidence. Journal of Applied Social Psychology, 37, 10771091. doi:10.1111/j.1559-1816.2007.00200.x

Fiedler, K., Messner, C., \& Bluemke, M. (2006). Unresolved problems with the "I", the "A", and the "T": A logical and psychometric critique of the Implicit Association Test (IAT). European Review of Social Psychology, 17, 74-147. doi:10.1080/10463280600681248

Fornell, C., \& Larcker, D. F. (1981). Evaluating structural equation models with unobservable variables and measurement error. Journal of Marketing Research, 18, 39-50. doi:10.2307/3151312

Foroni, F., \& Bel-Bahar, T. (2010). Picture-IAT versus Word-IAT: Level of stimulus representation influences on the IAT. European Journal of Social Psychology, 40, 321-337. doi:10.1002/ejsp.626

Gawronski, B., Morrison, M., Phills, C. E., \& Galdi, S. (2017). Temporal stability of implicit and explicit measures: A longitudinal analysis. Personality and Social Psychology Bulletin, 43, 300-312. doi:10.1177/0146167216684131

Glaser, M. O., \& Glaser, W. R. (1989). Time course analysis of the Stroop phenomenon. Journal of Experimental Psychology: Human Perception and Performance, 8, 875894. doi:10.1037//0096-1523.8.6.875

Gonzales, A. M., Dunlop, W. L., \& Baron, A. S. (2017). Malleability of implicit associations across development. Developmental Science, 1-13. doi:10.1111/desc.12481

Gorsuch, R. L. (1983). Factor Analysis (2nd ed.). New Jersey, USA: Laurence Erlbaum Associates. 
Greenberg, E., Dunleavy, E., \& Kutner, M. (2007). Literacy behind bars: Results from the 2003 National Assessment of Adult Literacy Prison Survey (NCES 2007-473). Washington, DC: National Center for Education Statistics.

Greenwald, A. G., McGhee, D. E., \& Schwartz, J. L. K. (1998). Measuring individual differences in implicit cognition: The Implicit Association Test. Journal of Personality and Social Psychology, 74, 1464-1480. doi:10.1037//00223514.74.6.1464

Greenwald, A. G., Nosek, B. A., \& Banaji, M. R. (2003). Understanding and using the Implicit Association Test: I. An improved scoring algorithm. Journal of Personality and Social Psychology, 85, 197-216. doi:10.1037/0022-3514.85.2.197

Grivas, G., Down, R., \& Carter, L. (2000). Psychology (2nd ed.). South Yarra: Macmillan.

Hair, J. F., Black, W. C., Babin, B. J., Anderson, R. E., \& Tatham, R. L. (2006). Multivariate Data Analysis (6th ed.). New Jersey: Prentice Hall.

Hofmann, W., \& Schmitt, M. (2008). Advances and challenges in the indirect measurement of individual differences at age 10 of the Implicit Association Test. European Journal of Psychological Assessment, 24, 207-209. doi:10.1027/1015-5759.24.4.207

Hu, L., \& Bentler, P. M. (1999). Cutoff criteria for fit indexes in covariance structure analysis: Conventional criteria versus new alternatives. Structural Equation Modelling, 6, 1-55.

Islam, M. R., \& Jahjah, M. (2001). Predictors of young Australians' attitudes toward Aboriginals, Asians and Arabs. Social Behavior and Personality, 29, 569-580. doi:10.2224/sbp.2001.29.6.569

Jöreskog, K. G. (1969). Structural analysis of covariance and correlation matrices. Psychometrika, 43, 443-477. doi:10.1007/BF02293808

Karpinski, A., \& Hilton, J. L. (2001). Attitudes and the Implicit Association Test. Journal of Personality and Social Psychology, 81, 774-788. doi:10.1037//0022.3514.81.5.774

Krause, S., Back, M. D., Egloff, B., \& Schmukle, S. C. (2010). Reliability of implicit selfesteem measures revisited. European Journal of Personality. doi:10.1002/per.792 McConahay, J. B., Hardee, B. B., \& Batts, V. (1981). Has racism declined in America? It depends on who is asking and what is asked? Journal of Conflict Resolution, 25, 563579. doi:10.1177/002200278102500401

Millisecond Software. (1996). Inquisit. Seattle, WA: Millisecond Software. Retrieved from http://www.millisecond.com/ 
Nesdale, D., \& Flesser, D. (2001). Social identity and the development of children's group attitudes. Child Development, 72, 506-517. doi:10.1111/1467-8624.00293

Nosek, B. A., Greenwald, A. G., \& Banaji, M. R. (2006). The Implicit Association Test at age 7: A methodological and conceptual review. In J. A. Bargh (Ed.), Social psychology and the unconscious: The automaticity of higher mental processes (pp. 265-292). New York: Psychology Press.

Nosek, B. A., \& Smyth, F. L. (2007). A multitrait-mutimethod validation of the Implicit Association Test: Implicit and explicit attitudes are related by distinct constructs. Experimental Psychology, 54, 14-29. doi:10.1027/1618-3169.54.1.14

Oswald, F. L., Mitchell, G., Blanton, H., Jaccard, J., \& Tetlock, P. E. (2013). Predicting ethnic and racial discrimination: A meta-analysis of IAT criterion studies. Journal of Personality and Social Psychology, 105, 171-192. doi:10.1037/a0032734

Oswald, F. L., Mitchell, G., Blanton, H., Jaccard, J., \& Tetlock, P. E. (2015). Using the IAT to predict ethnic and racial discrimination: Small effect sizes of unknown societal significance. Journal of Personality and Social Psychology, 108, 562-571. doi: $10.1037 / \mathrm{pspa0000023}$

Poitou, T., \& Pouget, P. (2012). Variability, noise and predictability in motor response times: Adaptation or misadaptation? In J. M. Norvilitis (Ed.), Contemporary Trends in ADHD Research (pp. 15-28): InTech. Retrieved from http://www.intechopen.com/books/contemporary-trends-in-adhd-research/variabilitynoise-and-predictability-in-motor-response-times-adaptation-or-misadaptation https://cdn.intechopen.com/pdfs/28228.pdf. doi:10.5772/28166

Rae, J. R., \& Olson, K. R. (2018). Test-retest reliability and predictive validity of the Implicit Association Test in Children. Developmental Psychology, 54, 308-330. doi: $10.1037 / \operatorname{dev} 0000437$

Raykov, T. (1997). Estimation of composite reliability for congeneric measures. Applied Psychological Measurement, 21, 173-184. doi:10.1177/01466216970212006

Rudolph, A., Schröder-Abé, M., Schütz, A., Gregg, A. P., \& Sedikides, C. (2008). Through a glass, less darkly? Reassessing convergent and discriminant validity in measures of implicit self-esteem. European Journal of Psychological Assessment, 24, 273-281. doi:10.1027/1015-5759.24.4.273 
Rutland, A., Cameron, L., Milne, A., \& McGeorge, P. (2005). Social norms and selfpresentation: Children's implicit and explicit intergroup attitudes. Child Development, $76,451-466$.

Schmidt, A. F., Banse, R., \& Imhoff, R. (2015). Indirect measures in forensic contexts. In T. M. Ortner \& F. J. R. van de Vijver (Eds.), Behavior-based assessment: Going beyond self-report in the personality, affective, motivation, and social domains (pp. 173-194). Gottingen: Hogrefe.

Siers, B. P., \& Christiansen, N. D. (2013). On the validity of implicit association measures of personality traits. Personality and Individual Differences, 54, 361-366. doi:10.1016/j.paid.2012.10.004

Slabbinck, H., De Houwer, J., \& van Kenhove, P. (2013). Convergent, discriminant, and incremental validity of the Pictorial Attitude Implicit Attitude Test and the Picture Story Exercise as a measure of the implicit power motive. European Journal of Personality, 27, 30-38. doi:10.1002/per.1846

Spector, P. E. (2006). Method variance in organizational research: Truth or urban legend? Organizational Research Methods, 9, 221-232. doi:10.1177/1094428105284955

Stanley, D., Phelps, E., \& Banaji, M. R. (2008). The neural basis of implicit attitudes. Current Directions in Psychological Science, 17, 164-170. doi:10.1111/j.14678721.2008.00568.x

Stülpnagel, R. v., \& Steffens, M. C. (2010). Prejudiced or just smart? Intelligence as a confounding factor in the IAT effect. Zeitschrift für Psychologie, 218, 51-53. doi:10.1027/0044-3409/a000008

Tabachnick, B. G., \& Fidell, L. S. (2013). Using Multivariate Statistics (6th ed.). Boston: Pearson Education.

Thomas, S. R. (2008). Investigating the Reliability and Validity of a Non-Verbal Adaptation of the IAT. (Masters of Clinical Psychology Masters Thesis), University of Tasmania, Hobart.

Thomas, S. R., Burton-Smith, R., \& Ball, P. (2007). Implicit Attitudes in Very Young Children: An adaptation of the IAT. Current Research in Social Psychology, 13, 7585.

United Nations. (2009). World Statistics Pocketbook; Economic and social affairs. New York: USA: United Nations Publications. 
Construct Validity of the Pictorial IAT

Williams, A., \& Steele, J. R. (2016). The reliability of child-friendly race-attitude implicit association tests. Frontiers in Psychology, 7, 1-11. doi:10.3389/fpsyg.2016.01576

Williams, J. K., \& Themanson, J. R. (2011). Neural correlates of the Implicit Association Test: Evidence for semantic and emotional processing. Social Cognitive and Affective Neuroscience, 6, 468-476. doi:10.1093/scan/nsq065 